\title{
Adverse drug reaction monitoring in patients of hypertension at a tertiary care hospital, Aurangabad, Maharashtra, India
}

\author{
Shruti Chandra $^{1 *}$, Sukhmeen Kaur ${ }^{1}$, Deepali Jayabhaye ${ }^{1}$, Amol Ubale ${ }^{2}$
}

\author{
${ }^{1}$ Department of Pharmacology, MGM Medical College and Research Centre, Maharashtra, India \\ ${ }^{2}$ Radiation oncology, Seth Nandlal Dhoot Hospital, Aurangabad, Maharashtra, India
}

Received: 22 April 2021

Accepted: 11 May 2021

*Correspondence:

Dr. Shruti Chandra,

Email: dr.shruti1204@gmail.com

Copyright: $\odot$ the author(s), publisher and licensee Medip Academy. This is an open-access article distributed under the terms of the Creative Commons Attribution Non-Commercial License, which permits unrestricted non-commercial use, distribution, and reproduction in any medium, provided the original work is properly cited.

\begin{abstract}
Background: Hypertension is one of the highest prevailing diseases worldwide. Due to long term therapy antihypertensive drugs are commonly associated with adverse drug reactions (ADRs). Therefore, the study was conducted with the objective to examine the incidence of different types of ADRs in drug treated hypertensive patients. Methods: Present study was a prospective cross sectional observational study carried out in the outpatient of department of medicine of MGM hospital, a tertiary care teaching hospital, in Aurangabad. 320 diagnosed hypertensive patients were studied. Questionnaire was asked and their prescription were analysed and follow up was done.

Results: Among 320 patient's 75 patients were reported ADR. Males accounted for higher percent of ADRs 46 (61\%) than females $29(38.6 \%)$. Most of the patients 147 (55.9\%) were on mono therapy. Calcium channel blocker was the frequently used class of drug, showed maximum number of ADR (30.6\%) followed by ACE inhibitor (28\%) and ARB $(21.3 \%)$. As per WHO-UMC scale, type of reactions and their percentage were as certain (9.3\%), Probable/ Likely $(64 \%)$, possible (22.6\%), and unlikely (4\%). According to Naranjo scale most of the reactions were possible (64\%). severity assessment is done by Hartwig and Siegel scale. No lethal ADR were reported. $4 \%$ reactions were severe, $32 \%$ were of moderate category and $64 \%$ were mild reactions.

Conclusions: Such type of studies are helpful in selection of appropriate medicines for hypertensive patients, enhancing patient adherence with the therapy by selecting medicines of lesser ADR profile, reducing unnecessary economic burden to the patients due to unwanted effects of the therapy.
\end{abstract}

Keywords: Hypertension, ADR monitoring, Causality assessment

\section{INTRODUCTION}

Hypertension is a chronic disease which is considered to be one of the major public health problem and a significant cardiovascular risk factor, where the systolic blood pressure is more than $140 \mathrm{mmHg}$ and diastolic blood pressure is more than $90 \mathrm{mmHg} .{ }^{1}$ It is considered to be one of the major public health problems and a significant cardiovascular risk factor. According to WHO each year, at least 7.1 million people die as a result of increased blood pressure. ${ }^{2}$ Hypertension is a global disease considered as the leading risk factor for cardiovascular diseases with significant health burden and accounts for 9.4 million deaths as well as $7.0 \%$ disability-adjusted life years (DALYs) of global DALYs in $2010 .^{3}$ In the year 2000, it was also found that the world was estimated to have 1 billion people with hypertension and predicted to increase to 1.56 billion by $2025 .{ }^{4}$ Outcome benefits have been demonstrated for Thiazide diuretics, beta blockers, long acting calcium channel antagonists, angiotensin converting enzyme inhibitors and angiotensin II receptor blockers. ADRs are considered among one of the leading causes of mortality. It was estimated that $6 \%$ of hospital 
admissions are estimated to be due to ADRs and about 6$15 \%$ of hospitalized patients experience serious ADR. Antihypertensive medications are frequently associated with ADRs which may limit treatment options and reduce patient compliance, which may hinder blood pressure control. It was believed that different discontinuation rates for various classes of antihypertensive medications are probably related to their different rates of adverse symptoms. ${ }^{1}$

According to the WHO definition, ADR is a response to a drug that is noxious and unintended and occurs at doses normally used in human for the prophylaxis, diagnosis, and treatment of disease, or for modification of physiological function. ${ }^{5}$ ADRs are considered among the leading causes of morbidity and mortality. Around $6 \%$ of hospital admissions are estimated to be due to ADRs and about $6-15 \%$ of hospitalized patient's experience a serious ADR. ${ }^{6}$ Monitoring of ADRs in India is in its infancy. A study conducted in the Indian capital reports that $22.3 \%$ of the patients experienced ADRs. ${ }^{7,8}$ Another report on ADR monitoring in northern India mentions that $5.9 \%$ of all visits to the medical department are drug related and ADRs accounted for $45 \%$ of events. ${ }^{9}$

Hence, there is a need to monitor the safety profile of all the medications on continuous basis and to review their therapeutic rationale in the light of add on information emanating out of the adverse drug reaction monitoring activities. Monitoring of ADRs is even more important in case of chronic ailments such as hypertension. More often than not, hypertension is an asymptomatic disorder and requires long term therapy predisposing to adverse drug events. ${ }^{10}$ ADR monitoring studies for monitoring ADRs related to antihypertensive agents have been previously conducted by many workers in different parts of the world. ${ }^{7,11,12}$

Therefore, the present study was conducted to evaluate the incidence and nature of ADRs in patients receiving antihypertensive drugs.

\section{METHODS}

\section{Study design}

A prospective cross sectional observational study was carried out in the outpatient of department of general medicine of MGM Hospital, a tertiary care teaching hospital, in Aurangabad. The study was started after approval from the institutional ethics committee and the hospital authorities.

\section{Selection criteria}

The study population included all diagnosed hypertensive patients according to JNC 8 and aged $>18$ years of either sex. Follow up of at least 3 months was done.
Patients who did not receive antihypertensive treatment and patients below 18 years of age were excluded. Patients were diagnosed hypertensive if they had at least 2 visits with diagnosis of hypertension or they had prescription of antihypertensive drug with one recording of elevated BP or they had elevated BP on two visits. Elevated BP was defined as systolic BP (SBP) $>140 \mathrm{mmHg}$ and diastolic BP (DBP) $>90 \mathrm{mmHg}^{13}$

Questionnaire was asked to the patients about their particulars, AHA received by the patient, dose and duration of treatment, any suspected ADR, onset and duration of ADR, system/s involved and any treatment received. The information was also sought from the patient's records wherever necessary. Data of antihypertensive drugs was recorded and grouped according to class of drug. Antihypertensive drugs were grouped in to seven groups: calcium channel blockers (CCB), beta blockers, diuretics, alfa blockers, angiotensin convertase enzyme inhibitors (ACEI), angiotensin receptor blockers (ARB), centrally acting drugs.

The probability that the adverse event was related to drug therapy was classified as definite, probable, possible, or doubtful. A definite reaction was one that followed a reasonable temporal sequence after a drug or in which a toxic drug level had been established in body fluids or tissues; followed a recognized response to the suspected drug and was confirmed by improvement on withdrawing the drug and reappeared on re-exposure. A probable reaction followed a reasonable temporal sequence after a drug, followed a recognized response to the suspected drug, was confirmed by withdrawal but not by exposure to the drug and could not be reasonably explained by the known characteristics of the patient's clinical state. A possible reaction followed a temporal sequence after a drug, possibly followed a recognized pattern to the suspected drug and could be explained by characteristics of the patient's disease. A reaction was defined as doubtful if it was likely related to factors other than a drug. ${ }^{14}$

The data obtained was entered in microsoft excel and further analysis done by SPSS (statistical package for the social sciences) version 25.0. The tables, figures and graphs were used to present the findings in the study patients.

\section{RESULTS}

In our study total 320 patients were included. Total number of ADR reported was 75 .

\section{Demographic distribution of patient}

The mean age (mean \pm SD) of the patients was $56.12 \pm 11.84$ years with range $18-80$ years and the median age was 58 
years (Table 1). Test of proportion showed most of the patients were significantly higher in the age group 41-60 years 147 (45.9\%). A total of 42 ADRs (56\%) were observed in the patient age group of 61-80 years, followed by $28(37.3 \%)$ in $41-60$ years, $5(6.6 \%)$ in $18-40$ years. Among 320 patients, 180 patients were male while 140 were females. 75 patients were reported ADR and males accounted for higher percent of ADRs 46 (61\%) than females $29(38.6 \%)$.

\section{Duration of hypertension}

Mean duration of hypertension (mean \pm SD) in the patients was $3.97 \pm 1.55$ (Table 2). Test of proportion showed 163 $(50.9 \%)$ patients were less than 3 years, followed by 138 $(43.1 \%)$ patients were between 4-6 years and least were 19 $(5.9 \%)$ were having history of $>7$ years. 39 patients among 163 of $<3$ years duration reports ADR which is highest in number.

Table 1: Distribution of age/gender group.

\begin{tabular}{|lllll|}
\hline Age group (in years) & Number of patients & Total (\%) & \multicolumn{2}{c|}{$\begin{array}{l}\text { ADR reported } \\
(\%)\end{array}$} \\
\cline { 2 - 5 } & Male $(\mathbf{n = 1 8 0})$ & Female $(\mathbf{n = 1 4 0 )}$ & $34(10.6)$ & $5(6.6)$ \\
\hline $\mathbf{1 8 - 4 0}$ & 21 & 12 & $147(45.9)$ & $28(37.3)$ \\
\hline $\mathbf{4 1 - 6 0}$ & 83 & 65 & $139(43.4)$ & $42(56)$ \\
\hline $\mathbf{6 1 - 8 0}$ & 76 & 63 & & \\
\hline ADR reported $(\boldsymbol{\%})$ & $46(61)$ & $29(38.6)$ & & \\
\hline
\end{tabular}

Table 2: Duration of hypertension.

\begin{tabular}{|llll|}
\hline Duration (in years) & Number of patients & Percent & $\begin{array}{l}\text { ADR reported } \\
(\mathbf{n}=\mathbf{7 5})\end{array}$ \\
\hline$<\mathbf{3}$ & 163 & 50.9 & 39 \\
\hline $\mathbf{4 - 6}$ & 138 & 43.1 & 31 \\
\hline$>\mathbf{7}$ & 19 & 5.9 & 5 \\
\hline
\end{tabular}

Table 3: Utilization pattern of different antihypertensive drugs.

\begin{tabular}{|c|c|c|c|}
\hline Treatments & Number of patients used antihypertensive drug & $\begin{array}{l}\text { ADR reported } \\
(n=75)\end{array}$ & $\begin{array}{l}\text { Percent of } \\
\text { ADR reported }\end{array}$ \\
\hline Monotherapy $(\mathrm{N}=147)$ & & $(n=31)$ & \\
\hline CCBs & 65 & 11 & 14.6 \\
\hline ARB & 29 & 5 & 6.6 \\
\hline ACEI & 17 & 8 & 10.6 \\
\hline Beta blocker & 19 & 4 & 5.3 \\
\hline Alpha blocker & 8 & 2 & 2.6 \\
\hline Diuretics & 9 & 1 & 1.3 \\
\hline Dual therapy $(\mathrm{N}=99)$ & & $(n=19)$ & \\
\hline $\mathrm{CCB}+\mathrm{ARB}$ & 38 & 7 & 9.3 \\
\hline $\mathrm{CCB}+$ beta blocker & 21 & 5 & 6.6 \\
\hline $\mathrm{CCB}+$ diuretic & 15 & 4 & 5.3 \\
\hline $\mathrm{ARB}+$ diuretic & 13 & 2 & 2.6 \\
\hline Others & 12 & 1 & 1.3 \\
\hline Triple therapy $(\mathrm{N}=45)$ & & $(n=17)$ & \\
\hline $\mathrm{CCB}+\mathrm{ARB}+$ diuretic & 27 & 8 & 10.6 \\
\hline $\begin{array}{l}\text { CCB+beta } \\
\text { blocker+diuretic }\end{array}$ & 12 & 7 & 9.3 \\
\hline Others & 8 & 2 & 2.6 \\
\hline Polytherapy (N=29) & 29 & 8 & 10.6 \\
\hline
\end{tabular}

Table 4: Adverse drug reactions.

\begin{tabular}{|llll|}
\hline Class of drugs & Adverse events experienced & $\begin{array}{l}\text { Number of } \\
\text { patients }\end{array}$ & $\%$ \\
\hline CCB & $\begin{array}{l}\text { Pedal edema, giddiness, headache, abdominal pain, } \\
\text { bradycardia }\end{array}$ & 23 & 30.6 \\
\hline
\end{tabular}

Continued. 


\begin{tabular}{|llll|}
\hline Class of drugs & Adverse events experienced & $\begin{array}{l}\text { Number of } \\
\text { patients }\end{array}$ & $\%$ \\
\hline ACE Inhibitor & $\begin{array}{l}\text { Dry cough, dizziness, headache, drowsiness, } \\
\text { diarrhea, hypotension, weakness, cough, rash, } \\
\text { metallic or salty taste. }\end{array}$ & 21 & 28 \\
\hline ARB & $\begin{array}{l}\text { Anxiety, nausea and vomiting, headache, } \\
\text { abdominal pain, restlessness, itching and } \\
\text { inflammatory swelling }\end{array}$ & 16 & 21.3 \\
\hline Beta blocker & $\begin{array}{l}\text { Constipation, nausea and vomiting, headache, } \\
\text { hypoglycemia, postural hypotension }\end{array}$ & 8 & 5.6 \\
\hline Diuretics & $\begin{array}{l}\text { Hypotension, muscle cramps, headache vertigo, } \\
\text { pain in legs, dysuria }\end{array}$ & 4 & 4 \\
\hline Other & Skin reaction & 3 & 4.3 \\
\hline
\end{tabular}

Table 5: WHO causality assessment of ADRs.

\begin{tabular}{|l|ll|}
\hline $\begin{array}{l}\text { Type of reactions } \\
\text { WHO causality assessment }\end{array}$ & Number of patients reported ADR (n=75) & Percent \\
\hline Certain & 7 & 9.3 \\
\hline Probable/likely & 48 & 64 \\
\hline Possible & 17 & 22.6 \\
\hline Unlikely & 3 & 4 \\
\hline Conditional/unclassified & - & - \\
\hline Unassessable/unclassifiable & - & - \\
\hline Causality assessment of ADRs by Naranjo scale & \\
\hline Definite & 7 & 9.3 \\
\hline Possible & 17 & 22.6 \\
\hline Probable & 48 & 64 \\
\hline Doubtful & 3 & 4 \\
\hline Severity of reported ADRs by modified Hartwig and Siegel scale & \\
\hline Lethal & - & - \\
\hline Severe & 3 & 4 \\
\hline Moderate & 24 & 32 \\
\hline Mild & 48 & 64 \\
\hline
\end{tabular}

\section{Utilization pattern of different antihypertensive drugs}

Test of proportion showed most of the patients 147 (45.9\%) were on mono therapy significantly higher than dual therapy, triple therapy and poly therapy, 99 (30.9\%), 45 (14\%), 29 (9\%), respectively (Table 3).

Out of 147 patients on mono therapy CCBs was the frequently used class of drug for mono therapy (65) among which 11 patients reported ADR. 99 patients were on dual drug therapies. $\mathrm{CCB}+\mathrm{ARB}$ were among the maximum utilized drugs. 45 patients were on triple drug therapy with $\mathrm{CCB}+\mathrm{ARB}+$ diuretic. Polytherapy was seen in 29 patients.

\section{ADRs and therapeutics class of suspected medication}

Total 75 patients were reported ADR. 28\% patients who were on ACEI and $30.6 \%$ patients receiving CCB reported side effect (Table 4).

\section{ADRs WHO causality assessment}

In the present study, causality assessment between the drug and suspected reaction was determined by using WHOUMC scale and Naranjo scale (Table 5). Causality assessment of ADRs was done using WHO-UMC scale which categorizes ADRs as certain, probable, possible and unlikely. Table 5 shows that type of reactions and their percentage are as certain $(9.3 \%)$, probable/likely $(64 \%)$, possible $(22.6 \%)$ and unlikely $(4 \%)$. According to Naranjo criteria, the ADRs are analyzed on the basis of a questionnaire comprising 10 questions in which each question is given a score of $+2,+1,0$ or -1 depending on the analysis. When totalled if the score is $>9$ : labelled as definite ADR, if 5-8: probable ADR, if 1-4: possible ADR, if 0: doubtful ADR. According to Naranjo scale, type of reactions and their percentage are as definite $(9.3 \%)$, possible $(64 \%)$, probable $(22.6 \%)$ and doubtful $(4 \%)$. Severity assessment is done by Hartwig and Siegel scale. Reactions can be lethal, severe, moderate and mild. In our study no lethal ADR were reported. $4 \%$ reactions were 
severe, $32 \%$ were of moderate category and $64 \%$ were mild reactions.

\section{DISCUSSION}

As per the study criteria total 320 cases of hypertensive patients (both sex) of different age group ranges from 1880 years were collected. Maximum number of patients were from the age group of 41-60 (45.9\%) years followed by $61-80(43.4 \%)$ and least number in $18-40(10.6 \%)$ years of age of patients are from this age group (Table 1). Plasma renin falls by $17 \%$ each decade which may be the possible reason of hypertension in older population. ${ }^{15}$ Similar results were obtained by Sharma et al. ${ }^{15}$ A total of 42 ADRs $(56 \%)$ were observed in the patient age group of 61-80 years, followed by $28(37.3 \%)$ in $41-60$ years, $5(6.6 \%)$ in $18-40$ years. Kumar et al also observed that $35.3 \%$ patients who developed ADR were from age group 41-50 years. Least were from 20-30 years $(2.9 \%){ }^{2}$

Total 320 patients were there, including $180(56.2 \%)$ males and $140(43.7 \%)$ females, showing a predominance of male population (Table 1). The hypothetical cause of higher number of male patients is elevated levels of androgen such as testosterone as they play a role in elevation of blood pressure. ${ }^{16}$ A similar study was also conducted by Sharma et al in 2018 which is supporting our study. ${ }^{15}$ In our study among 320 patients, 75 patients were reported ADR and males accounted for higher percent of ADRs (61\%) than females $(38.6 \%)$. Khurshid et al observed that females experienced more ADRs which is opposite to our result. ${ }^{17}$

In our study, most of the patients 147 (45.9\%) were on mono therapy which is significantly higher than dual therapy, triple therapy and poly therapy, 99 (30.9\%), 45 $(14 \%), 29(9 \%)$ respectively (Table 3$)$. Sharma et al observed that among 150 patients, $142(94.7 \%)$ patients were on poly therapy significantly higher than mono therapy, double therapy and triple therapy $(0.7 \%), 0(0 \%)$, $7(4.7 \%)$ respectively of all the collected cases. ${ }^{15}$

Out of 65 patients received CCB among monotherapy 11 $14.6 \%$ patients reported ADR which is maximum. Among dual therapy patients receiving $\mathrm{CCB}$ and $\mathrm{ARB}$ reported ADR in 7 patients, $9.3 \%$ while 8 patients $(10.6 \%)$ reported ADR among 27 patients who received triple therapy of $\mathrm{CCB}, \mathrm{ARB}$ and diuretic (Table 3). Also, CCB was the frequently used drug for monotherapy. In a study by Mohd et al the most commonly prescribed antihypertensive among elderly patients was amlodipine. ${ }^{18}$ This is also in consonance with the recommendations of the JNC on prevention, detection, evaluation and treatment of high blood pressure guidelines which state that low dose of different classes of antihypertensive drugs is more beneficial than a high dose of one. ${ }^{19}$

Among the total 75 ADR cases, CCBs contributed the most to $23(30.6 \%)$ ADRs followed by ACEI in $21(28 \%)$, ARB (16 or $21.3 \%$ ), beta blocker $(10.8 \%)$ and diuretic (4 or $5.3 \%$ ) as shown in Table 4 . Similar results were obtained by a study conducted by Paudel et al where they observed among the total 67 ADR cases, CCBs contributed to 22 (32.84\%) ADRs followed by ACEI in 17 (25.38\%), ARB (12 or $17.91 \%)$, diuretic (10 or $14.92 \%){ }^{20}$

The common side effect seen with ACEI were dry cough, dizziness, headache, diarrhea, hypotension, weakness, cough, rash, metallic or salty taste. The cough is typically irritating, dry and nonproductive and is not dose related. Dry cough is mediated by the accumulation in the lungs of bradykinin, substance $\mathrm{P}$, and/or prostaglandins. ${ }^{20}$ The common complaints with the usage of CCB were pedal edema, giddiness, headache, abdominal pain, bradycardia (Table 4). Oedema has been reported as the most common problem with amlodipine by Ramesh et al. ${ }^{21}$ Edema occurs with CCBs because of vasodilation in the distal arterioles, thereby leading to increased intravascular capillary pressures and increased venous pressures, at least in the lower extremities and eventually leakage of fluid into the extracellular space. ${ }^{22}$

According to WHO-UMC scale maximum number of ADRs in probable class $(64 \%)$ followed by possible (22.6\%), unlikely (9.3\%) and certain class (4\%) (Table 5). Sharma et al observed that that type of reactions and their percentage are as certain (5.6\%), possible (62.9\%), probable/likely $(19.5 \%)$ and unlikely $(12.0 \%) .{ }^{15}$ In our study, the result of Naranjo algorithm is represented by Table 5. Most of the ADR fall under probable category $(64 \%)$ follower by possible $(22.6 \%)$, definite $(9.3 \%)$ and doubtful (4\%) respectively. Paudel et al also observed the similar results. According to Sharma et al Naranjo scale showed certain $(56 \%)$, probable $(24 \%)$, possible $(13 \%)$ and unlikely $(08 \%)$. Khurshid et al also observed similar results. ${ }^{15,20}$

Moreover, as per the modified Hartwig and Siegel's scale maximum number of ADRs was mild category (64\%) and lowest in severe type (4\%) of reaction (Table 5). No ADRs were found in lethal type of reaction. These findings were consistent with the literature reported by Ganachari et al and Singh et al. ${ }^{23,24}$

\section{CONCLUSION}

In this pharmacovigilance study, CCBs were found to be the most frequently associated drugs with ADRs followed by ACEI, ARB, beta blocker and diuretics. On Naranjo's probability scale, more than half of the reported ADRs were classified as possible. Such type of studies are helpful in selection of appropriate medicines for hypertensive patients, enhancing patient adherence with the therapy by selecting medicines of lesser ADR profile, reducing unnecessary economic burden to the patients due to unwanted effects of the therapy. It is important to remember that most ADR's would subside once the offending agent is discontinued or dosage reduced. Therefore, monitoring of adverse effects due to antihypertensive medications, particularly of serious nature is mandatory. Hence, physicians, clinical pharmacists and 
other health care professionals should report life threatening complications, hospitalizations (initial or prolonged) associated with anti-hypertensive drugs. The overall goal of treating hypertension is to reduce hypertension associated morbidity and mortality.

Funding: No funding sources

Conflict of interest: None declared

Ethical approval: The study was approved by the Institutional Ethics Committee

\section{REFERENCES}

1. Sudhakar R, George MK, Yasaswini B, Sundararajan $\mathrm{N}$, Mariyam MAS. Adverse drug reactions associated with anti-hypertensive drugs and its management. Int J Pharm Sci Res. 2016;7(3):898-905.

2. Kumar RV, Raghu RV, Prasad BG, Mohanta GP, Manna PK. A study of adverse drug reactions due to antihypertensive drugs in a tertiary care teaching hospital Int. J Pharm Life Sci. 2011;2(5):767-72.

3. Olowofela AO, and Isah AO. A Profile of adverse effects of antihypertensive medicines in a tertiary care clinic in Nigeria. Ann Afr Med. 2017;16(3):114-9.

4. Joffres M, Falaschetti E, Gillespie C, Robitaille C, Loustalot F, Poulter N, et al. Hypertension prevalence, awareness, treatment and control in national surveys from England, the USA and Canada, and correlation with stroke and ischaemic heart disease mortality: a cross-sectional study. BMJ Open. 2013;3(8):003423.

5. International drug monitoring: the role of national centres. Report of a WHO meeting. World Health Organ Tech Rep Ser. 1972;498:1-25.

6. Kumar VR, Ram VR, Prasad BG, Mohanta GP, Manna PK. A study of adverse drug reactions due to antihypertensive drugs in a tertiary care teaching hospital. Int J Pharm Life Sci. 2011;2(5):767-72.

7. Wallander MA, Dimenas E, Svardsudd K, Wiklund I. Evaluation of three methods of symptom reporting in a clinical trial of felodipine. Eur J Clin Pharmacol. 1991;41:187-96.

8. Parthasarathi G, Olsson S. Adverse drug reactions. In: Parthasarathi G, Nyfort-Hansen K, Nahata MC, eds. A textbook of clinical pharmacy practice. 1st ed. Chennai: Orient Longman Pvt Ltd; 2004: 84-102.

9. Garg KC, Singhal KC, Kumar S. Monitoring the adverse profile of atenolol a collaborative study. Indian J Physiol Pharmacol. 1993;37(3):213-6.

10. Uppsala Monitoring Centre. Fact sheet: The use of the World Health Organization-Uppsala Monitoring Centre (WHO-UMC) system for standardised case causality assessment, 2006. Available at: http://whoumc.org/graphics/4409.pdf. Accessed on 6 April 2021.

11. Dhikav V, Singh S, Anand KS. Adverse drug reaction monitoring in India. $\mathrm{J}$ Indian Acad Clin Med. 2004;5(1):27-3.

12. Riley J, Wilton LV, Shakir SA. A post marketing observational study to assess the safety of mibefradil in the community of England. Int $\mathrm{J}$ Clin Pharmacol Ther. 2002;40(6):241-8.

13. Singh RB, Suh IL, Singh VP, Chaithiraphan S, Laothavorn P, Sy RG, et al. Hypertension and stroke in Asia: Prevalence, control and strategies in developing countries for prevention. J Hum Hypertens. 2000;14(10-11):749-63.

14. Naranjo CA, Busto U, Sandor P, Ruiz I, Roberts EA, Janecek E, et al. A method for estimating the probability of adverse drug reactions. Clin Pharmacol Ther. 1981;30(2):239-45.

15. Amit S, Tanpreet KB, Vishal G, Mahendra SR, Manik C. Drug utilization study on hypertensive patients and assessment of medication adherence to jnc- 8 guidelines in north indian tertiary care hospital: a cross-sectional study. Adv Res Gastroentero Hepatol. 2018;9(1):555751.

16. Tasneem S, Fouzia N. Drug utilization study in ischemic heart diseases associated with diabetes and hypertension. International $\mathbf{J}$ Pharma Biosci. 2010;1(3):1-4.

17. Khurshid F, Aqil M, Alam MS, Kapur P Pillani KK. Monitoring of adverse drug reactions associated with antihypertensive medicines at a university teaching hospital in New Delhi. Daru. 2012;20(1):34.

18. Mohd AH, Mateti UV, Konuru V, Parmar MY, Kunduru BR. A study on prescribing patterns of antihypertensives in geriatric patients. Perspect Clin Res. 2012;3(4):139-42.

19. James PA, Oparil S, Carter BL, Cushman WC, Himmelfarb CD, Handler J, et al. Evidence-based guideline for the management of high blood pressure in adults. Report from the panel members appointed to the eighth joint national committee (JNC 8). JAMA. 2014;311(5):507-20.

20. Paudel S, Chetty MS, Laudari S, Subedi ND. Adverse drug reactions of antihypertensive agents at tertiary care hospital in central Nepal. JCMS Nepal. 2017;13(2):284-9.

21. Ramesh M, Pandit J, Parthasarathi G. Adverse drug reactions in a south Indian hospital-their severity and cost involved. Pharmacoepidemiol Drug Saf. 2003; 12:687-92.

22. Brunton L, Chabner B, Knollman B. Goodman and Gilman's The Pharmacological Basis of Therapeutics. 12th ed. Boston: McGraw Hill; 2011.

23. Ganachari MS, Wadhwa T, Walli S, Disha AK, Aggarwal A. Trigger tools for monitoring and reporting of adverse drug reactions: A Scientific tool for efficient reporting. Open Access Scientif Rep. 2013;2:1-5.

24. Singh H, Kumar BN, Sinha T, Dulhani N. The incidence and nature of drug-related hospital admission: a 6-month observational study in a tertiary health care hospital. J Pharmacol Pharmacother. 2011;2(1):17-20.

Cite this article as: Chandra S, Kaur S, Jayabhaye $\mathrm{D}$, Ubale A. Adverse drug reaction monitoring in patients of hypertension at a tertiary care hospital, Aurangabad, Maharashtra, India. Int J Basic Clin Pharmacol 2021;10:720-5. 